\title{
Prevalence, Characteristics, and Clinical Course of Neuropathic Pain in Primary Care Patients Consulting With Low Back-related Leg Pain
}

\author{
Sarah A. Harrisson, PhD, *† Reuben Ogollah, PhD, $\neq$ Kate M. Dunn, PhD,* \\ Nadine E. Foster, DPhil, ${ }^{*}$ and Kika Konstantinou, PhD*†
}

Objectives: Little is known about the epidemiology of neuropathic pain in primary care patients consulting with low back-related leg pain. We aimed to describe prevalence, characteristics, and clinical course of low back-related leg pain patients with and without neuropathic pain, consulting with their family doctor in the United Kingdom.

Materials and Methods: This was a prospective cohort study. Data were collected using a standardized baseline clinical examination and self-report questionnaires at baseline, 4,12 , and 36 months. We identified cases of neuropathic pain using 3 definitions: 2 based on clinical diagnosis (sciatica, with and without evidence of nerve root compression on magnetic resonance imaging), one on the self-report version of Leeds Assessment for Neurological Symptoms and Signs. Differences between patients with and without neuropathic pain were analyzed comparing each definition. Clinical course (mean pain intensity measured as the highest of leg or back pain intensity: mean of 3 Numerical Rating Scales, each 0 to 10) was investigated using linear mixed models over 36 months.

Results: Prevalence of neuropathic pain varied from $48 \%$ to $74 \%$ according to definition used. At baseline, patients with neuropathic pain had more severe leg pain intensity, lower pain self-efficacy, more patients had sensory loss than those without. Distinct profiles were apparent depending on neuropathic pain definition. Mean pain

Received for publication February 3, 2020; revised May 26, 2020; accepted July 28, 2020.

From the *School of Medicine, Primary Care Versus Arthritis Centre, Keele University; †Haywood Hospital, Midlands Partnership Foundation Trust, Staffordshire; and \$Nottingham Clinical Trials Unit, University of Nottingham, Nottingham, UK.

During the period in which this work was undertaken S.A.H. was supported by a National Institute for Health Research (NIHR) (England and Wales) Clinical Doctoral Fellowship funded through an NIHR Research Professorship for N.E.F. (NIHR-RP011-015). N.E.F. is also a Senior NIHR Investigator. K.K. was supported by a Higher Education Funding Council for England (UK)/National Institute for Health Research Senior Clinical Lectureship. The views expressed in this publication are those of the author(s) and not necessarily those of the NHS, the NIHR or the Department of Health and Social Care. This work also relates to an Education and Continued Professional Development (level 2) award by the Musculoskeletal Association of Chartered Physiotherapists (MACP) (UK) and a Travel Fellowship awarded by the Society of Back Pain Research (UK) to S.A.H. in 2016. The remaining authors declare no conflict of interest.

Reprints: Sarah A. Harrisson, PhD, Primary Care Centre Versus Arthritis, Research Institute for Primary Care and Health Sciences, Keele University, Staffordshire ST5 5BG, UK (e-mail: s.a. harrisson@keele.ac.uk).

Supplemental Digital Content is available for this article. Direct URL citations appear in the printed text and are provided in the HTML and PDF versions of this article on the journal's website, www. clinicalpain.com.

Copyright (C) 2020 Wolters Kluwer Health, Inc. All rights reserved.

DOI: 10.1097/AJP.0000000000000879 intensity reduced after 4 months (6.1 to 3.9 [sciatica]), most rapidly in cases defined by clinical diagnosis.

Discussion: This research provides new information on the clinical course of neuropathic pain and a better understanding of neuropathic pain in low back-related leg pain patients consulting in primary care.

Key Words: low back pain, leg pain, primary care, neuropathic pain, epidemiology

(Clin J Pain 2020;36:813-824)

$\mathrm{N}$ europathic pain (NP), defined as pain caused by injury or disease of the somatosensory system, ${ }^{1}$ is considered to be challenging to manage. The symptoms of NP, which may include feelings of burning, electric-shock and/ or prickling, ${ }^{2}$ can be very distressing for patients. There is no gold standard for defining cases of NP but there is some consensus for a hierarchical grading system to assist researchers and clinicians to identify cases of NP. ${ }^{1}$ Patients with a pain condition, plausible clinical history and with relevant findings from neurological examination meet the criteria for having "possible" NP. With the addition of appropriate findings from diagnostic tests, patients meet the criteria for having "probable" NP. The majority of patients with NP are managed in primary care, ${ }^{3}$ even if consulting with severe and bothersome pain. In primary care, where clinicians are nonspecialists, NP screening tools (eg, self-report version of Leeds Assessment of Neuropathic Symptoms and Signs (s-LANSS) ${ }^{4}$ have been suggested as useful to identify patients with possible NP. ${ }^{5}$

Low back pain (LBP) is thought to be one of the most common NP presentations ${ }^{6}$ and is the leading cause of disability globally. ${ }^{7}$ Leg pain related to back pain (LBLP) is one of the most common presentations of $\mathrm{LBP}^{8,9}$ and is associated with increased pain, disability and poorer quality of life compared with LBP alone. ${ }^{10}$ For this reason there is an argument that LBLP patients should be considered as distinct for research purposes from those with LBP. ${ }^{11}$ LBLP is clinically diagnosed as having sciatica (also termed lumbar spinal nerve root pain or radicular pain) or referred leg pain, where sciatica is thought to be neuropathic ${ }^{12}$ and referred leg pain to be nociceptive.

There are specific pharmacological and nonpharmacological treatments (physiotherapy, cognitive behavioral therapy) available to LBLP patients with and without NP in primary care. Guidelines advocate that NP medications are considered for patients with sciatica. ${ }^{13,14}$ A diagnostic approach is important when it enables the provision of timely 
and targeted interventions as in acute illnesses, it is not clear whether this approach is useful for LBLP patients consulting in primary care. For many LBLP patients consulting in primary care, identifying NP does not provide sufficient knowledge or evidence of likely future health outcomes. ${ }^{15}$ It is widely thought that LBLP patients with NP do worse over time compared with those without, but evidence from a recent systematic review ${ }^{16}$ highlighted the paucity of evidence describing the prognosis of LBLP patients with NP consulting in primary care.

The aims of this study were to describe: (1) prevalence of NP in LBLP patients consulting in primary care; (2) characteristics of LBLP patients with NP; (3) the clinical course of LBLP patients with NP at baseline in terms of pain intensity over short, intermediate, and long-term timepoints. Given there is no perfect standard for identifying cases of NP, we provide and compare data on prevalence, characteristics and clinical course, by describing cases using clinical definitions for NP and also a NP screening tool.

\section{MATERIALS AND METHODS}

\section{Study Design and Patient Recruitment}

This is secondary analysis of a prospective, multicentre cohort study, the Assessment and Treatment of Leg pain Associated with the Spine (ATLAS) study, of LBLP patients consulting and receiving treatment in primary care. Ethical approval was granted by the South Birmingham Research Ethics Committee (REC $\mathrm{ref}^{10} / \mathrm{H} 1207 / 82$ ) in October 2010 for the original study, and by NRES Committees North of Scotland (REC $\mathrm{ref}^{13} / \mathrm{NS} / 0170$ ) for the longer-term followup. All analyses in this report were nested within this program of work. Adults aged 18 years and over with LBLP of any duration and severity, who consulted with their family doctor, were invited to take part in the ATLAS study. For the full details of the recruitment procedure see the ATLAS study protocol, ${ }^{17}$ the flow of patients in the ATLAS study is summarized in Figure 1. Patients were considered to have LBLP if they presented with leg pain that spread from the lower back beyond the gluteal fold to anywhere in the leg. Pain was considered to include unpleasant sensations such as pins and needles or numbness. Patients were excluded if there was suspected serious spinal pathology, previous spinal surgery, pregnancy, they were receiving physiotherapy treatment (or osteopathy or chiropractic) or were under the care of a specialist consultant in secondary care for the same condition, those with serious physical or mental comorbidity that would prevent them attending the research clinic or undergoing the study's procedures, or inability to read and speak English.

All participants in the study were assessed by physiotherapists and a neurological examination was carried out as part of the clinical examination as recommended in LBP guidelines $^{19}$ and specialist books (eg, Examination of the Lumbar Region in Neuromusculoskeletal Examination and Assessment, pages 329 to 330). ${ }^{20}$ At the time of the clinical examination, a clinical diagnosis of either sciatica or referred leg pain was made. In this research, a clinical diagnosis of sciatica was characterized by leg pain that may radiate to beyond the knee and into the foot or toes, and may be accompanied by muscle weakness and/or reflex change and/or pins and needles or numbness (paresthesia), in a specific nerve root(s) distribution. ${ }^{21}$ The term sciatica is indicative of nerve root compression (NRC) causing radicular pain with or without neurological deficits and the criteria for clinical

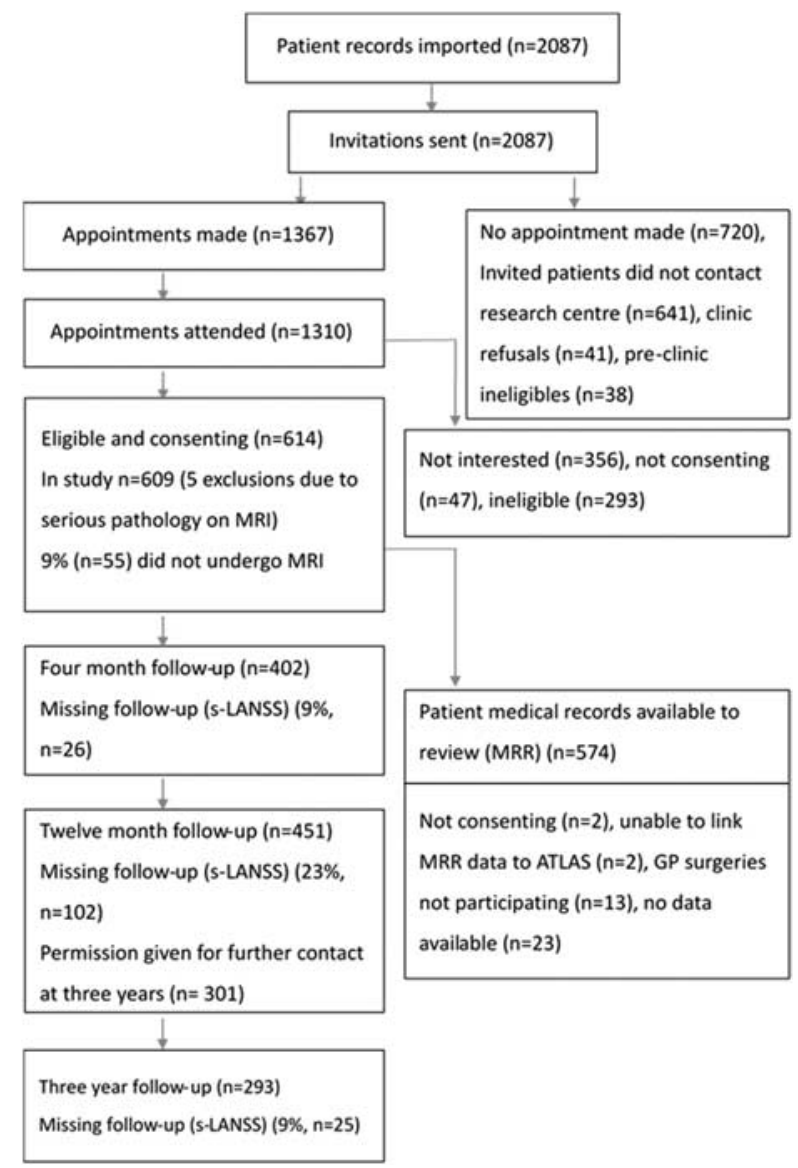

FIGURE 1. Study flow diagram (adapted from Konstantinou et $\mathrm{al}^{18}$ ). Adaptations are themselves works protected by copyright. So in order to publish this adaptation, authorization must be obtained both from the owner of the copyright in the original work and from the owner of copyright in the translation or adaptation. MRR indicates medical records review; s-LANSS, selfreport version of Leeds Assessment for Neurological Symptoms and Signs.

diagnosis was predetermined following consensus from a Delphi study. ${ }^{22}$

All physiotherapists in the ATLAS study were given training in the study's procedures. There was fair agreement between physiotherapists in this study when making a diagnosis of sciatica or referred leg pain. The full details of the agreement and reliability among the clinicians in the ATLAS study when diagnosing low back-related leg pain are provided elsewhere. ${ }^{23}$ All patients in the ATLAS study were invited for a magnetic resonance imaging (MRI) scan within 10 days of attending their assessment at the ATLAS research clinic, except in cases where this imaging was contraindicated, or when the patient did not wish to have a scan, or when an MRI scan was already available in the previous 6 months for the same clinical presentation. Data used in this analysis were collected at baseline and at 3 follow-up points at 4 months, 12 months, and 3 years using postal self-complete questionnaires.

\section{Treatment Pathways}

Treatment plans for patients in the study were agreed between the treating physiotherapist and the patient, and 
according to current best clinical evidence and practice guidelines. For those patients where physiotherapy management was indicated, up to 6 (on average) treatment sessions (of $30 \mathrm{~min}$ ) were delivered over 6 to 8 weeks. If a patient's symptoms worsened or failed to improve, pathways were in place so that appropriate referrals could be made to specialist spinal services for further assessment and management including onward referral to spinal surgeons and pain specialists.

\section{Selected Characteristics of Interest}

The characteristics chosen to describe LBLP patients with and without NP were based on sociodemographic information (age, sex, socioeconomic status based on type of work, smoking status and body mass index), health status (presence of diabetes, general health, ${ }^{24}$ fatigue, and sleep difficulties), information about pain (mean back pain intensity, mean leg pain intensity, ${ }^{25}$ pain described as burning, duration of pain, pain location, presence of widespread pain), limitations in activities (back and leg pain related disability using the Roland and Morris Disability Questionnaire) ${ }^{26}$ leg version, ${ }^{27}$ psychological variables (symptoms of depression and anxiety using the Hospital Anxiety and Depression Scale ${ }^{28}$ ), pain self-efficacy beliefs using the Pain Self-Efficacy Questionnaire, ${ }^{29}$ findings from neurological examination (presence of muscle weakness, tendon reflex, sensation to pin prick, presence of pins and needles, pain affecting the color of patients skin, presence of allodynia or hyperalgesia in the leg(s), neural tension test and imaging using MRI), and the number of pain medications used. See Table S1 (Supplemental Digital Content 1, http://links.lww.com/CJP/A685), for full details of all the characteristics collected in this study.

\section{Data Analysis}

Cases of NP were identified using 3 definitions of NP: 2 based on clinical diagnosis (sciatica ${ }^{21,22}$ with and without evidence of NRC on MRI), one on the self-report using s-LANSS ${ }^{4}$ (see Table 1 for a detailed description of each of the 3 definitions of NP used in this research). Prevalence was estimated for 3 definitions of NP. Descriptive statistics (mean and SD for continuous variables and frequency and

\begin{tabular}{|c|c|c|}
\hline Approach & Description of Definition & $\begin{array}{l}\text { Level of } \\
\text { Certainty }\end{array}$ \\
\hline $\begin{array}{l}\text { Clinical } \\
\text { examination }\end{array}$ & $\begin{array}{l}\text { Clinical diagnosis of sciatica* with } \\
\text { evidence of possible or clear } \\
\text { nerve root compression on MRI } \\
\text { scan }\end{array}$ & Probable $\dagger$ \\
\hline $\begin{array}{l}\text { Clinical } \\
\text { examination }\end{array}$ & $\begin{array}{l}\text { Clinical diagnosis of sciatica* } \\
\text { without evidence of nerve root } \\
\text { compression on MRI scan }\end{array}$ & Possible $\dagger$ \\
\hline $\begin{array}{l}\text { Neuropathic pain } \\
\text { screening tool }\end{array}$ & S-LANSS score of $\geq 12$ & Possible: \\
\hline $\begin{array}{l}\text { Clinical } \\
\text { examination }\end{array}$ & $\begin{array}{l}\text { Clinical diagnosis of referred leg } \\
\text { pain }\end{array}$ & Unlikely† \\
\hline \multicolumn{3}{|c|}{$\begin{array}{l}{ }^{*} \text { Described by Koes et } \mathrm{al}^{21} \text { criteria for clinical diagnosis agreed by con- } \\
\text { sensus by Konstantinou et al. }{ }^{22} \\
\dagger \text { Described by Treede et al } 1^{1} \text { and later updated by Finnerup et al. }{ }^{14} \\
\text { †Described by Smith et al. } \\
\text { MRI indicates magnetic resonance imaging; s-LANSS, self-report ver- } \\
\text { sion of Leeds Assessment for Neurological Symptoms and Signs. }\end{array}$} \\
\hline
\end{tabular}

percentage for categorical variables) were used to describe characteristics of interest in those with NP for each of the NP definitions. Logistic regression was used to examine the association between NP (based on the 3 definitions), characteristics of interest and was based on the analysis of complete cases.

For describing the clinical course, linear mixed models, with a NP indicator variable (according to NP definition used) by time interaction, were used to estimate the unadjusted mean and $95 \%$ confidence intervals (CIs) of pain intensity at all 3 follow-up time-points. CIs were obtained to evaluate the uncertainty of estimates taking into account the missing data. ${ }^{30}$ Margins plots were used to graphically summaries the information on the clinical course.

All statistical analyses were performed using Stata version 14.0. ${ }^{31}$ The STrengthening the Reporting of OBservational studies in Epidemiology (STROBE) checklist for cohort studies was used when writing the report. ${ }^{32}$

\section{Measures of Clinical Course}

Pain intensity scores at baseline, 4 months, 12 months, and 3 years, were used to describe the clinical course of this patient population. Pain intensity was determined as the highest of mean leg pain intensity or mean back pain intensity in the previous 2 weeks, where leg pain intensity was determined as the mean of three 0 to 10 NRS for current, usual and least leg pain over the previous 2 weeks, and back pain intensity as the mean of current, usual and least back pain over the previous 2 weeks. ${ }^{25}$

\section{RESULTS}

\section{Study Population}

In total, 609 patients with LBLP were eligible and consented to participate in the study; patients received a clinical diagnosis of either referred leg pain or sciatica and 554 had an MRI. Three of 609 patients did not complete all 7 items of the s-LANSS. In total, $402(66.0 \%)$ completed the study questionnaire at 4 months, $450(73.9 \%)$ at 12 months, and $316(51.9 \%)$ at 3 years. Patients who responded to follow-up at 4 months were older than nonresponders (mean 54 y compared with $42 \mathrm{y}$ ), fewer scored 12 or greater on s-LANSS ( $45 \%$ compared with $55 \%$ ), a slightly higher proportion had a clinical diagnosis of sciatica $(77 \%$ compared with 70\%) and they had slightly lower LBLP-related disability (mean Roland and Morris Disability Questionnaire 12.1 compared with 13.7) at baseline. This was consistent at 12 months and 3 years. Nearly 9 of $10(88.0 \%)$ patients in the ATLAS cohort received a course of physiotherapy treatment and $11.4 \%$ of patients were referred to specialist services for further treatment or investigations. A slightly higher proportion $(14.3 \%)$ of patients with NP based on a clinical diagnosis of sciatica with evidence NRC were referred for an epidural injection or to spinal surgeons. Table S2 (Supplemental Digital Content 2, http://links.lww. com/CJP/A686) gives details on the care provided to patients in the ATLAS study according to the 3 definitions of NP.

\section{Prevalence of NP in LBLP Patients}

The prevalence of NP was $74.2 \%$ based on a clinical diagnosis of sciatica (452/609), $48.8 \%$ based on s-LANSS $(296 / 606)$, and $45.5 \%$ based on sciatica with evidence of possible or clear NRC (252/554). Just under one quarter $(23.0 \%, 127 / 551)$ of LBLP patients were defined as having 


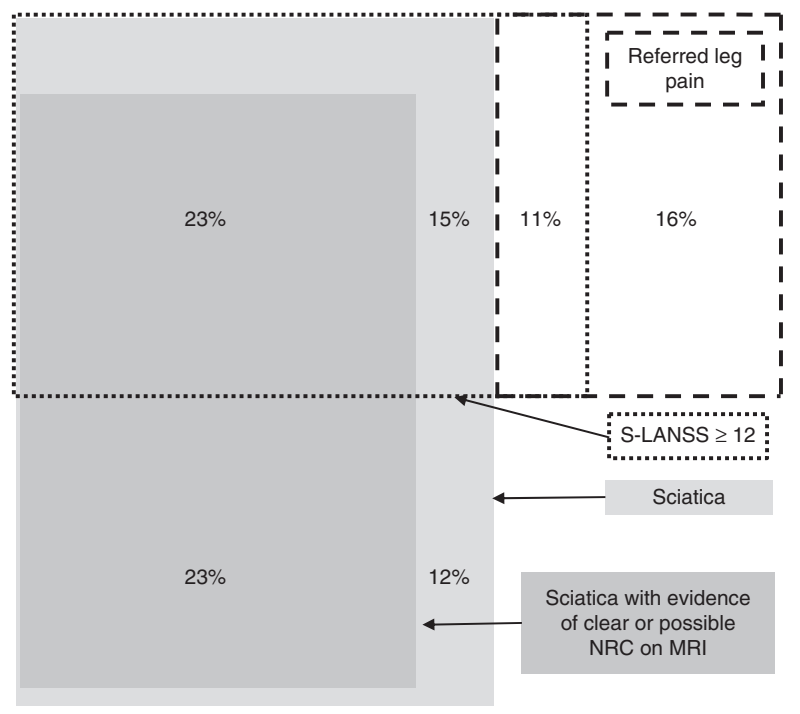

FIGURE 2. Venn diagram depicting the overlap between patients with and without neuropathic pain at baseline based on 3 case definitions. MRI indicates magnetic resonance imaging; NRC, nerve root compression; s-LANSS, self-report version of Leeds Assessment for Neurological Symptoms and Signs.

NP using all 3 definitions. Nearly 4 in 10 patients $(38.3 \%$, $232 / 606$ ) were defined as having NP based on s-LANSS and clinical diagnosis of sciatica. Around 1 in $10(10.7 \%, 61 / 606)$ were defined as having NP based on s-LANSS, but were not by clinical diagnosis of sciatica either with or without evidence of NRC. The distributions and overlap of LBLP patients with or without NP, based on the 3 definitions, are summarized in Figure 2.

\section{Characteristics of LBLP Patients With NP}

The profile of patients with NP based on s-LANSS was quite distinct compared with those without; they were more often current smokers, presented with more severe back pain intensity, more scored higher for depression and anxiety, more had an increased response to either nonpainful or painful stimuli on clinical examination and more often used 2 or more pain medications compared with those without NP. The profile of patients with neuropathic LBLP based on s-LANSS was also quite distinct compared with those with NP based on clinical diagnosis of sciatica either with or without evidence of NRC on MRI. There were few differences in terms of health status, limitations in activities, psychological variables, and pain medication use between patients with NP based on clinical diagnosis of sciatica compared with those more stringently defined as having a clinical diagnosis of sciatica with evidence of NRC based on MRI.

The characteristics of LBLP patients with and without NP based on s-LANSS, those with NP based on a clinical diagnosis of sciatica, and those with LBLP based on clinical diagnosis of sciatica plus evidence of possible or clear NRC on MRI, respectively are provided in Tables $2-4$. LBLP patients with NP, across all $3 \mathrm{NP}$ definitions, reported more severe leg pain (for a 1-unit increase in NRS score for leg pain intensity, the odds $[95 \% \mathrm{CI}]$ presenting with NP based on s-LANSS increased by $1.20[1.12,1.29]$, the odds of having a clinical diagnosis of sciatica increased by 1.32 $[1.21,1.44]$ and the odds of having a clinical diagnosis of sciatica plus evidence of NRC based on MRI increased by $1.29[1.19,1.40])$; patients with pain below the knee were more likely to present with NP compared with those without with the odds ratios $(95 \% \mathrm{CI})$ of $1.98(1.38,2.87), 9.03(6.00$, $13.60)$, and $4.18(2.74,6.37)$ for definition based on s-LANSS, clinical diagnosis of sciatica and clinical diagnosis of sciatica plus evidence of NRC based on MRI, respectively; and more had a weaker belief in the ability to cope with normal activities despite the pain (pain self-efficacy) compared with those without (for a 1 unit decrease in Pain Self-Efficacy Questionnaire score, the odds of presenting with NP based on s-LANSS increased by $0.97(0.97$, $0.98)$, by $0.98(0.98,0.997)$ for those with a clinical diagnosis of sciatica and by $0.98(0.97,0.99)$ for those with a clinical diagnosis of sciatica plus evidence of NRC based on MRI).

On the basis of findings from neurological examination and consistently across all 3 definitions of NP, patients with a reduction in sensation to pin-prick were more likely to present with NP (odds ratios [95\% CI] 1.64 [1.16 to 2.33], 3.87 [2.43, $6.16], 1.76[1.22,2.54]$ for definition based on s-LANSS, clinical diagnosis of sciatica and clinical diagnosis of sciatica plus evidence of NRC based on MRI, respectively) and those with a significant reduction or absence of tendon reflex (odds ratios [95\% CI] 1.68 [1.06, 2.65], 4.42 [2.09, 9.38], 5.63 [3.22, 9.86] for definition based on s-LANSS, clinical diagnosis of sciatica and clinical diagnosis of sciatica plus evidence of NRC based on MRI, respectively) were more likely to present with NP compared with those without. The presence of mild muscle weakness (myotomal) was found in $100 \%$ of patients with a clinical diagnosis of sciatica with or without evidence of NRC on MRI, and was associated with those patients with NP based on s-LANSS.

\section{Clinical Course}

Pain intensity decreased over time and most of the change occurred between baseline and 4 months, irrespective of the NP case definition used. Mean pain intensity in patients with NP at baseline (across the 3 definitions) ranged from 6.1 to 6.3 , decreasing to between 3.8 and 4.3 at 4 months (Figs. 3A-C). Improvement in pain intensity plateaued around 4 months and changed very little up to 36 months for all NP definitions (mean pain intensity of patients with NP at 3 years ranged from 3.3 to 3.9 for the 3 definitions).

Patients with NP (based on s-LANSS) had higher mean pain intensity $(95 \% \mathrm{CI})$ compared with those without at 12 months $(4.4[4.1,4.7]$ vs. $3.0[2.7,3.3])$, but not at 3 years $(3.9$ $[3.5,4.3]$ vs. $3.0[2.7,3.4])$. Patients with NP (based on a clinical diagnosis of sciatica) had lower mean pain intensity compared with those without at 12 months $(3.6[3.3,3.8]$ vs. $4.0[3.5,4.4])$ and at 3 years $(3.3[3.1,3.6]$ vs. $3.8[4.4,4.3])$. Those patients with sciatica plus MRI evidence of NRC had lower mean pain intensity at 4 months $(3.8[3.5,4.2]$ vs. $4.1[3.8,4.3]), 12$-months $(3.3[3.0,3.7]$ vs. $4.0[3.7,4.4])$, and 3 years $(3.3[3.9,3.6]$ vs. 3.6 $[3.2,4.0])$.

\section{DISCUSSION}

This is the first prospective cohort including LBLP patients consulting in primary care with NP, and the first time that data on the clinical course of neuropathic LBLP over short, intermediate, and long-term time-points, has been reported. Prevalence estimates of NP in this patient population varied from $48 \%$ to $74 \%$ depending on the NP definition used. Irrespective of case definition, our study shows that the presence of NP in LBLP patients consulting in primary care, is 
TABLE 2. Baseline Characteristics of Patients With Neuropathic Pain Based on s-LANSS

\begin{tabular}{|c|c|c|c|}
\hline \multirow[b]{2}{*}{ Characteristics* } & \multicolumn{2}{|c|}{ Neuropathic Pain (s-LANSS $\geq 12$ ) } & \multirow[b]{2}{*}{$\begin{array}{c}\text { Unadjusted Odds Ratio } \\
(95 \% \text { CI })\end{array}$} \\
\hline & $\begin{array}{c}\text { Yes, } n=293 \\
(48.4 \%)\end{array}$ & $\begin{array}{c}\text { No, } n=313 \\
(51.7 \%)\end{array}$ & \\
\hline \multicolumn{4}{|l|}{ Sociodemographic characteristics } \\
\hline Female $(\mathrm{n}=606)$ & $200(68.3)$ & $182(58.2)$ & $1.55(1.10,2.16)$ \\
\hline Age $(n=606)$, mean $(S D)$ & $49.8(13.5)$ & $50.4(14.2)$ & $1.00(0.99,1.01)$ \\
\hline \multicolumn{4}{|l|}{ Socioeconomic status $(\mathrm{n}=590)$} \\
\hline Higher managerial, administrative and professional occupations & 49 (17.4) & $79(25.7)$ & 1 \\
\hline Intermediate occupations & $71(25.2)$ & $86(27.9)$ & $1.33(0.83,2.14)$ \\
\hline Routine and manual occupations & $142(50.4)$ & $140(45.5)$ & $1.64(1.07,2.5)$ \\
\hline Never worked and long-term unemployed & $20(7.1)$ & $3(1.0)$ & $10.75(3.03,38.07)$ \\
\hline \multicolumn{4}{|l|}{ Smoking status $(\mathrm{n}=605)$} \\
\hline Never & $99(33.9)$ & $127(40.6)$ & 1 \\
\hline Ex-smoker & $80(27.4)$ & $105(33.6)$ & $0.98(0.66,1.45)$ \\
\hline Current & $113(38.7)$ & $81(25.9)$ & $1.79(1.21,2.64)$ \\
\hline $\begin{array}{l}\text { BMI }(\mathrm{n}=598), \text { mean }(\mathrm{SD}) \\
\quad\left(\mathrm{kg} / \mathrm{m}^{2}\right)\end{array}$ & $29.7(6.1)$ & $29.5(5.6)$ & $1.01(0.98,1.03)$ \\
\hline \multicolumn{4}{|l|}{ Health status } \\
\hline Self-reported diabetes $(n=606)$ & $25(8.5)$ & $22(7.0)$ & $1.23(0.68,2.24)$ \\
\hline \multicolumn{4}{|l|}{ Self-reported general health $(n=605)$} \\
\hline Excellent/very good & $52(17.8)$ & $93(29.7)$ & 1 \\
\hline Good & $93(31.9)$ & $78(24.9)$ & $2.13(1.35,3.36)$ \\
\hline Fair & $116(39.7)$ & $123(39.3)$ & $1.69(1.10,2.58)$ \\
\hline Poor & $31(10.6)$ & $19(6.1)$ & $2.92(1.50,5.67)$ \\
\hline Fatigue $(\mathrm{n}=593)$ & $214(74.3)$ & $198(64.9)$ & $1.56(1.10,2.23)$ \\
\hline Sleep difficulties $(n=601)$ & $258(88.4)$ & $253(81.9)$ & $1.68(1.06,2.66)$ \\
\hline \multicolumn{4}{|l|}{ Pain characteristics } \\
\hline Back pain intensity $(0-10)(n=600)$, mean $(S D)$ & $5.5(1.6)$ & $5.1(1.6)$ & $1.15(1.04,1.27)$ \\
\hline Leg pain intensity $(0-10)(n=578)$, mean $(S D)$ & $5.8(2.3)$ & $4.7(2.4)$ & $1.20(1.12,1.29)$ \\
\hline Constant pain symptoms $(\mathrm{n}=594)$ & $221(75.4)$ & $177(58.8)$ & $2.15(1.51,3.06)$ \\
\hline Pain described as burning pain $(\mathrm{n}=606)$ & $165(56.3)$ & $55(17.6)$ & $6.05(4.18,8.77)$ \\
\hline \multicolumn{4}{|l|}{ Duration of back pain symptoms in current episode $(n=604)$} \\
\hline$<6 \mathrm{wk}$ & 98 (33.7) & $119(38.0)$ & 1 \\
\hline $6-12 w k$ & $65(22.3)$ & $60(19.2)$ & $1.32(0.87,2.04)$ \\
\hline$>3 \mathrm{mo}$ & $128(44.0)$ & $134(42.8)$ & $1.16(0.81,1.66)$ \\
\hline \multicolumn{4}{|l|}{ Duration of leg pain symptoms in current episode $(n=580)$} \\
\hline$<6 \mathrm{wk}$ & $110(39.3)$ & $141(47.0)$ & 1 \\
\hline $6-12 \mathrm{wk}$ & $61(21.8)$ & $58(19.3)$ & $1.18(0.75,1.86)$ \\
\hline$>3 \mathrm{mo}$ & $109(38.9)$ & $101(33.7)$ & $1.41(0.96,2.08)$ \\
\hline Widespread pain $\dagger(n=590)$ & $124(42.9)$ & $125(41.5)$ & $1.05(0.74,1.47)$ \\
\hline Leg pain worse $(n=604)$ & $138(47.4)$ & 139 (44.4) & $1.13(0.82,1.56)$ \\
\hline \multicolumn{4}{|l|}{ Pain location $(n=606)$} \\
\hline Pain below the knee & $228(77.8)$ & $200(63.9)$ & $1.98(1.38,2.87)$ \\
\hline Pain in 1 leg & $211(72.0)$ & $244(78.0)$ & $0.73(0.50,1.06)$ \\
\hline \multicolumn{4}{|c|}{ Limitations in activities, participation and risk of persistent disabling pain, mean (SD) } \\
\hline LBLP-related disability (RMDQ, 0-23) $(\mathrm{n}=606)$ & $13.8(5.6)$ & $11.5(5.6)$ & $1.08(1.05,1.11)$ \\
\hline \multicolumn{4}{|l|}{ Risk of persistent disability due to back pain (STarT Back) $(n=530)$} \\
\hline Low risk & $29(10.2)$ & $53(17.6)$ & 1 \\
\hline Medium risk & $120(42.3)$ & $154(51.0)$ & $1.57(0.92,2.7)$ \\
\hline High risk & $135(47.5)$ & $95(31.5)$ & $2.7(1.56,4.7)$ \\
\hline \multicolumn{4}{|l|}{ Psychological characteristics } \\
\hline \multicolumn{4}{|l|}{ Depression (HADS) $(n=606)$} \\
\hline Normal $(0-7)$ & $155(52.9)$ & $235(75.1)$ & 1 \\
\hline Possible (mild) cases $(8-10)$ & $67(22.9)$ & $52(16.6)$ & $1.95(1.29,2.96)$ \\
\hline Probable (moderate/severe) cases $(\geq 11)$ & $71(24.2)$ & $26(8.3)$ & $4.14(2.53,6.78)$ \\
\hline Anxiety (HADS) $(\mathrm{n}=604)$ & & & \\
\hline Normal $(0-7)$ & $118(40.6)$ & $196(62.6)$ & 1 \\
\hline Possible (mild) cases $(8-10)$ & $60(20.6)$ & $60(19.2)$ & $1.66(1.08,2.54)$ \\
\hline Probable (moderate/severe) cases $(\geq 11)$ & $113(38.8)$ & $57(18.2)$ & $3.30(2.22,4.87)$ \\
\hline Pain self-efficacy (PSEQ, 0-60) $\$(\mathrm{n}=590)$, mean $(\mathrm{SD})$ & $30.8(14.6)$ & $37.4(13.8)$ & $0.97(0.96,0.98)$ \\
\hline Neurological examination findings & & & \\
\hline Muscle strength $\S(n=606)$ & & & \\
\hline $5 / 5$ & $231(78.8)$ & $270(86.3)$ & 1 \\
\hline $4 / 5$ & $56(19.1)$ & $36(11.5)$ & $1.81(1.15,2.86)$ \\
\hline 0 to $3 / 5$ & $6(2.1)$ & $7(2.2)$ & $1.00(0.33,3.02)$ \\
\hline
\end{tabular}

(Continued) 
TABLE 2. (continued)

\begin{tabular}{|c|c|c|c|}
\hline \multirow[b]{2}{*}{ Characteristics* } & \multicolumn{2}{|c|}{ Neuropathic Pain (s-LANSS $\geq 12$ ) } & \multirow[b]{2}{*}{$\begin{array}{l}\text { Unadjusted Odds Ratio } \\
(95 \% \text { CI })\end{array}$} \\
\hline & $\begin{array}{l}\text { Yes, } n=293 \\
\quad(48.4 \%)\end{array}$ & $\begin{array}{l}\text { No, } n=313 \\
\quad(51.7 \%)\end{array}$ & \\
\hline \multicolumn{4}{|l|}{ Reflex (tendon) change $(n=606)$} \\
\hline None & $222(75.8)$ & $265(84.7)$ & 1 \\
\hline Slightly reduced & $19(6.5)$ & $11(3.5)$ & $2.06(0.96,4.43)$ \\
\hline Significantly reduced or absent & $52(17.8)$ & $37(11.8)$ & $1.68(1.06,2.65)$ \\
\hline \multicolumn{4}{|l|}{ Sensation to pin-prick in the $\operatorname{leg}(s)(n=606)$} \\
\hline Normal & $150(51.2)$ & $204(65.2)$ & 1 \\
\hline Reduction or loss to pin-prick & $143(48.8)$ & $109(34.8)$ & $1.78(1.29,2.47)$ \\
\hline Presence of allodynia or hyperalgesia in the $\operatorname{leg}(s) \|(n=606)$ & $40(13.7)$ & $17(5.4)$ & $2.75(1.52,4.97)$ \\
\hline $\begin{array}{l}\text { Neural tension test } \\
\quad(\text { any positive test, } \mathrm{n}=606)\end{array}$ & $168(57.3)$ & $165(52.7)$ & $1.21(0.87,1.66)$ \\
\hline Pins and needles in the $\operatorname{leg}(s)(n=606)$ & $209(71.3)$ & $84(28.7)$ & $5.80(4.08,8.23)$ \\
\hline Pain affects the color of patients skin $(n=606)$ & $61(20.8)$ & $6(1.9)$ & $13.45(5.70,31.7)$ \\
\hline \multicolumn{4}{|l|}{ Neuroimaging } \\
\hline Clear or possible nerve root compression $(n=551)$ & $142(52.8)$ & $154(54.6)$ & $0.93(0.66,1.30)$ \\
\hline \multicolumn{4}{|l|}{ Pain medications } \\
\hline \multicolumn{4}{|l|}{ No. pain medications\# $(n=606)$} \\
\hline None & $34(11.6)$ & $49(15.7)$ & 1 \\
\hline One & $103(35.2)$ & $141(45.1)$ & $1.05(0.63,1.75)$ \\
\hline Two or more & $156(53.2)$ & $123(39.3)$ & $1.83(1.11,3.01)$ \\
\hline
\end{tabular}

Figures are frequencies (percentages) unless stated otherwise as mean (SD).

Odds ratio (CIs) in italics characteristics associated with neuropathic pain.

* Denominator varies for some characteristics due to missing data or not applicable case.

†Widespread pain was defined as pain present above and below the waist, in the right-hand and left-hand sides of the body and in the axial skeleton.

$\$$ Higher scores on PSEQ reflect stronger self-efficacy beliefs.

§Muscle strength was tested according to a 6-point grading scale where; 0. No visible flicker of movement or contraction. 1. Flicker of movement. 2. Full active movement with gravity counterbalanced. 3. Full active movement against gravity but not applied resistance. 4 . Full active movement against gravity and some applied resistance. 5. Full active movement against gravity and strong resistance.

$\|$ Hyperalgesia is an increased pain response to painful stimuli. Allodynia is pain response to nonpainful stimuli (eg, brush strokes).

Neural tension tests; straight leg raise, femoral stretch and slump test.

\#Pain medications include self-reported history of prescribed medications and those purchased over the counter.

BMI indicates body mass index; CI, confidence intervals; HADS, Hospital Anxiety and Depression Scale; LBLP, leg pain related to back pain; PSEQ, Pain Self-Efficacy Questionnaire; RMDQ, Roland Morris Disability Questionnaire leg version; S-LANSS, self-report version of Leeds Assessment for Neurological Symptoms and Signs neuropathic pain scale.

common. LBLP patients with NP based on s-LANSS presented with a more severe profile overall compared with those with NP based on a clinical diagnosis of sciatica with or without MRI evidence of NRC. We found several characteristics that were common across the 3 definitions of NP; higher leg pain intensity, lower pain self-efficacy, higher proportion of patients with pain below the knee, sensory deficits in the painful leg, mild muscle weakness (myotomal) and reduction in reflex. On average, there was early improvement in the clinical course in terms of pain intensity reduction followed by a plateau, with clinical course being worse only for those patients with NP identified using the s-LANSS compared with those without.

Many patients with NP defined by a diagnosis of sciatica were not identified as having NP based on s-LANSS. This finding is consistent with previous literature reporting that many patients with NP based on a clinical diagnosis of sciatica were not identified as having NP based on NP screening tools such as PainDETECT and DN4. ${ }^{16,33}$ Screening tools such as s-LANSS which are completed by self-report and where higher scores indicate the possible presence of NP, may not be representative of underlying neuropathic mechanisms specifically, in these patients with sciatica.

This research provides the highest quality evidence to date on the characteristics of this patient population. As expected, the characteristics of patients with NP varied depending on the method used to define cases. Patients with NP based on s-LANSS presented with a distinctly different profile compared with those with NP based on clinical diagnosis of sciatica. Depression, anxiety and use of 2 or more pain medications were more common in patients with NP based on s-LANSS compared with those with NP based on clinical diagnosis of sciatica with or without MRI evidence of NRC. This is consistent with previous research of patients with and without NP based on clinical examination, ${ }^{33-35}$ which found fewer differences in pain duration, LBLP-related disability, depression, anxiety, and health-related quality of life between patients with and without NP compared with those research studies using screening tools to identify cases of NP. ${ }^{36-38}$ None of the previous studies ${ }^{33-38}$ aimed to describe the characteristics of LBLP patients with or without NP and, in part, were limited by either small sample sizes or poorly defined comparator groups.

The clinical course of patients with and without NP at baseline, in terms of pain intensity, showed some consistent similarities across the $3 \mathrm{NP}$ definitions used. On average, most improvement in pain intensity occurred between baseline and 4 months, followed by a plateau through to 3 years. This pattern of mean improvement is similar to the clinical course of LBP patients ${ }^{39}$ and patients with other musculoskeletal pain conditions. ${ }^{40}$ 
TABLE 3. Baseline Characteristics of Patients With Neuropathic Pain Defined by Clinical Diagnosis of Sciatica

\begin{tabular}{|c|c|c|c|}
\hline \multirow[b]{2}{*}{ Characteristics* } & \multicolumn{2}{|c|}{$\begin{array}{c}\text { Neuropathic Pain } \\
\text { (Clinical Diagnosis of Sciatica) } \\
\end{array}$} & \multirow[b]{2}{*}{$\begin{array}{c}\text { Unadjusted Odds Ratio } \\
(95 \% \mathrm{CI})\end{array}$} \\
\hline & $\begin{array}{c}\text { Yes, } n=452 \\
(74.2 \%)\end{array}$ & $\begin{array}{c}\text { No, }, n=157 \\
(25.8 \%)\end{array}$ & \\
\hline \multicolumn{4}{|l|}{ Sociodemographic characteristics } \\
\hline Female $(n=609)$ & $277(61.3)$ & $106(67.52)$ & $0.76(0.52,1.12)$ \\
\hline Age $(n=609)$, mean $(S D)$ & $50.4(14.0)$ & $49.5(13.7)$ & $1.01(0.99,1.02)$ \\
\hline \multicolumn{4}{|l|}{ Socioeconomic status $(\mathrm{n}=593)$} \\
\hline Higher managerial, administrative, and professional occupations & $89(20.3)$ & $40(25.8)$ & 1 \\
\hline Intermediate occupations & $120(27.4)$ & $38(24.5)$ & $1.42(0.84,2.39)$ \\
\hline Routine and manual occupations & $210(48.0)$ & $73(47.1)$ & $1.29(0.82,2.04)$ \\
\hline Never worked and long-term unemployed & $18(4.3)$ & $4(2.6)$ & $2.13(1.68,6.68)$ \\
\hline \multicolumn{4}{|l|}{ Smoking status $(\mathrm{n}=608)$} \\
\hline Never & $169(37.5)$ & $58(36.9)$ & 1 \\
\hline Ex-smoker & $131(29.1)$ & $56(35.7)$ & $0.80(0.52,1.24)$ \\
\hline Current & $151(33.5)$ & $43(27.4)$ & $1.21(0.77,1.89)$ \\
\hline BMI $(\mathrm{n}=601)$, mean $(\mathrm{SD})\left(\mathrm{kg} / \mathrm{m}^{2}\right)$ & $29.8(6.0)$ & $29.1(5.6)$ & $1.02(0.99,1.05)$ \\
\hline \multicolumn{4}{|l|}{ Health status } \\
\hline Self-reported diabetes $(n=608)$ & $37(8.2)$ & $11(7.0)$ & $1.18(0.59,2.38)$ \\
\hline \multicolumn{4}{|l|}{ Self-reported general health $(n=608)$} \\
\hline Excellent/very good & $111(24.6)$ & $35(22.3)$ & 1 \\
\hline Good & $124(27.5)$ & $48(30.6)$ & $0.81(0.49,1.35)$ \\
\hline Fair & $177(39.3)$ & $63(40.1)$ & $0.89(0.55,1.43)$ \\
\hline Poor & $39(8.7)$ & $11(7.0)$ & $1.12(0.52,2.41)$ \\
\hline Fatigue $(\mathrm{n}=593)$ & $214(74.3)$ & $198(64.9)$ & $1.18(0.79,1.78)$ \\
\hline Sleep difficulties $(n=604)$ & $385(85.8)$ & $129(83.2)$ & $0.82(0.50,1.36)$ \\
\hline \multicolumn{4}{|l|}{ Pain characteristics } \\
\hline Back pain intensity $(0-10)(\mathrm{n}=603)$, mean $(\mathrm{SD})$ & $5.3(1.6)$ & $5.3(1.6)$ & $0.98(0.87,1.09)$ \\
\hline Leg pain intensity $(0-10)(\mathrm{n}=581)$, mean $(\mathrm{SD})$ & $5.6(2.3)$ & $4.2(2.2)$ & $1.32(1.21,1.44)$ \\
\hline Constant pain symptoms $(\mathrm{n}=597)$ & $305(68.7)$ & $96(62.8)$ & $1.30(0.89,1.91)$ \\
\hline Pain described as burning pain $(n=609)$ & $166(36.7)$ & $55(35.0)$ & $1.08(0.74,1.57)$ \\
\hline \multicolumn{4}{|l|}{ Duration of back pain symptoms in current episode $(n=607)$} \\
\hline$<6 \mathrm{wk}$ & $174(38.6)$ & $44(28.2)$ & 1 \\
\hline $6-12 w k$ & $96(21.3)$ & $30(19.2)$ & $0.81(0.48,1.37)$ \\
\hline$>3 \mathrm{mo}$ & $181(40.1)$ & $82(52.6)$ & $0.59(0.37,0.85)$ \\
\hline \multicolumn{4}{|l|}{ Duration of leg pain symptoms in current episode $(n=583)$} \\
\hline$<6 \mathrm{wk}$ & $192(44.2)$ & $59(39.6)$ & 1 \\
\hline $6-12 w k$ & $94(21.7)$ & $26(17.5)$ & $1.11(0.66,1.87)$ \\
\hline$>3 \mathrm{mo}$ & $148(34.1)$ & $64(43.0)$ & $0.71(0.47,1.07)$ \\
\hline Widespread pain $\dagger(\mathrm{n}=592)$ & $171(38.8)$ & $79(52.3)$ & $0.58(0.40,0.84)$ \\
\hline Leg pain worse $(n=607)$ & $251(55.8)$ & $28(17.8)$ & $5.81(3.71,9.10)$ \\
\hline \multicolumn{4}{|l|}{ Pain location $(n=609)$} \\
\hline Pain below the knee & $375(83.0)$ & $55(35.0)$ & $9.03(6.00,13.60)$ \\
\hline Pain in 1 leg & $368(81.4)$ & $89(56.7)$ & $3.35(2.26,4.97)$ \\
\hline \multicolumn{4}{|l|}{ Limitations in activities, participation and risk of persistent disabling pain } \\
\hline LBLP-related disability (RMDQ) $(0-23)(n=609)$, mean $(S D)$ & $12.9(5.7)$ & $11.9(5.7)$ & $1.03(0.997,1.06)$ \\
\hline \multicolumn{4}{|l|}{ Risk of persistent disability due to back pain (STarT Back) $(n=589)$} \\
\hline Low risk & $53(12.1)$ & $29(19.1)$ & 1 \\
\hline Medium risk & $212(48.5)$ & $64(42.1)$ & $1.81(1.06,3.09)$ \\
\hline High risk & $172(39.4)$ & $59(38.8)$ & $1.60(0.93,2.74)$ \\
\hline \multicolumn{4}{|l|}{ Psychological characteristics } \\
\hline \multicolumn{4}{|l|}{ Depression (HADS) $(n=609)$} \\
\hline Normal $(0-7)$ & $295(65.3)$ & $97(61.8)$ & 1 \\
\hline Possible (mild) cases (8-10) & $82(18.1)$ & 37 (23.6) & $0.73(0.46,1.14)$ \\
\hline Probable (moderate/severe) cases $(\geq 11)$ & $75(16.6)$ & $23(14.7)$ & $1.07(0.64,1.80)$ \\
\hline Anxiety (HADS) $(\mathrm{n}=607)$ & & & \\
\hline Normal $(0-7)$ & $249(55.2)$ & $67(43.0)$ & 1 \\
\hline Possible (mild) cases $(8-10)$ & $86(19.1)$ & $34(21.8)$ & $0.68(0.42,1.10)$ \\
\hline Probable (moderate/severe) cases $(\geq 11)$ & $116(25.7)$ & $55(35.3)$ & $0.57(0.37,0.86)$ \\
\hline Pain self-efficacy (PSEQ, 0-60) $+(\mathrm{n}=593)$, mean $(\mathrm{SD})$ & $33.3(14.7)$ & $36.6(13.9)$ & $0.98(0.97,0.997)$ \\
\hline Neurological examination findings & & & \\
\hline Muscle strength $\S(\mathrm{n}=608)$ & & & \\
\hline $5 / 5$ & $347(76.8)$ & $156(100.0)$ & 1 \\
\hline $4 / 5$ & $92(20.4)$ & 0 & - \\
\hline 0 to $3 / 5$ & $13(2.9)$ & 0 & - \\
\hline
\end{tabular}


TABLE 3. (continued)

\begin{tabular}{|c|c|c|c|}
\hline \multirow[b]{2}{*}{ Characteristics* } & \multicolumn{2}{|c|}{$\begin{array}{c}\text { Neuropathic Pain } \\
\text { (Clinical Diagnosis of Sciatica) }\end{array}$} & \multirow[b]{2}{*}{$\begin{array}{c}\text { Unadjusted Odds Ratio } \\
(95 \% \text { CI })\end{array}$} \\
\hline & $\begin{array}{l}\text { Yes, } n=452 \\
(74.2 \%)\end{array}$ & $\begin{array}{l}\text { No, } n=157 \\
(25.8 \%)\end{array}$ & \\
\hline \multicolumn{4}{|l|}{ Reflex (tendon) change $(n=609)$} \\
\hline None & $341(75.4)$ & $149(94.9)$ & 1 \\
\hline Slightly reduced & $30(6.6)$ & 0 & - \\
\hline Significantly reduced or absent & $81(17.9)$ & $8(5.1)$ & $4.42(2.09,9.38)$ \\
\hline \multicolumn{4}{|l|}{ Sensation to pin-prick in the $\operatorname{leg}(\mathrm{s})(\mathrm{n}=609)$} \\
\hline Normal & $226(50.0)$ & $130(82.8)$ & 1 \\
\hline Reduction or loss to pin-prick & $226(50.0)$ & $27(17.2)$ & $4.81(3.06,7.6)$ \\
\hline Presence of allodynia or hyperalgesia in the $\operatorname{leg}(\mathrm{s}) \|(\mathrm{n}=609)$ & $47(10.4)$ & $11(7.0)$ & $1.54(0.78,3.05)$ \\
\hline Neural tension test (any positive test, $\mathrm{n}=609$ ) & $324(71.7)$ & $11(7.0)$ & $33.60(17.61,64.10)$ \\
\hline Pins and needles in the leg(s) $(n=609)$ & $256(56.6)$ & $49(31.2)$ & $2.88(1.96,4.23)$ \\
\hline Pain affects the color of patients skin $(n=609)$ & $51(11.3)$ & $16(10.3)$ & $1.12(0.62,2.03)$ \\
\hline \multicolumn{4}{|l|}{ Neuroimaging } \\
\hline Clear or possible nerve root compression $(n=554)$ & $252(60.7)$ & $45(32.4)$ & $3.23(2.15,4.85)$ \\
\hline \multicolumn{4}{|l|}{ Pain medication } \\
\hline \multicolumn{4}{|l|}{ No. pain medications\# $(n=609)$} \\
\hline None & $61(13.5)$ & $23(14.7)$ & 1 \\
\hline One & $177(39.2)$ & $69(44.0)$ & $0.97(0.56,1.68)$ \\
\hline Two or more & $214(47.4)$ & $65(41.4)$ & $1.24(0.71,2.16)$ \\
\hline $\begin{array}{l}\text { Figures are frequencies (percentages) unless stated otherwise as mea } \\
\text { Odds ratio (CIs) in italics characteristics associated with neuropath } \\
\text { *Denominator varies for some characteristics due to missing data o } \\
\text { †Widespread pain was defined as pain present above and below the } \\
\text { \$Higher scores on PSEQ reflect stronger self-efficacy beliefs } \\
\text { \$Muscle strength was tested according to a 6-point grading scale wh } \\
\text { active movement with gravity counterbalanced. 3. Full active movement } \\
\text { some applied resistance. 5. Full active movement against gravity and st } \\
\text { ॥yyperalgesia is an increased pain response to painful stimuli. Alloc } \\
\text { १Neural tension tests; straight leg raise, femoral stretch and slump t } \\
\text { \#Pain medications include self-reported history of prescribed medic } \\
\text { BMI indicates body mass index; CI, confidence intervals; HADS, Ho } \\
\text { Self-Efficacy Questionnaire; RMDQ, Roland Morris Disability Question }\end{array}$ & $\begin{array}{l}\text { ble case. } \\
\text { right-hand and } \\
\text { isible flicker of } m \\
\text { ity but not applie } \\
\text { ce. } \\
\text { response to non- } \\
\text { ose purchased or } \\
\text { ty and Depressior } \\
\text { rsion. }\end{array}$ & $\begin{array}{l}\text { nd sides of the b } \\
\text { nt or contraction } \\
\text { tance. } 4 \text {. Full act } \\
\text { stimuli (eg, bru } \\
\text { counter. } \\
\text {; LBLP, leg pain }\end{array}$ & $\begin{array}{l}\text { and in the axial skeleton. } \\
\text { Flicker of movement. 2. Full } \\
\text { novement against gravity and } \\
\text { rokes). } \\
\text { ted to back pain; PSEQ, Pain }\end{array}$ \\
\hline
\end{tabular}

One of the assumptions underpinning this research is that the prognosis of patients with NP is considered to be worse compared with those without. The clinical course of patients with NP based on s-LANSS was worse than those without 12 months after initially consulting in primary care with LBLP, but this was not the case for the 2 other definitions of NP. The finding that the clinical course is worse in patients with $\mathrm{s}$-LANSS $\geq 12$ is consistent with previous research using PainDETECT to define NP cases. ${ }^{36}$ We did not find that patients with "probable" NP (those patients with a clinical diagnosis of sciatica with MRI evidence of NRC) has a worse clinical course than those with "possible" NP (those more broadly defined by the clinical diagnosis of sciatica without MRI evidence of NRC).

In patients with a clinical diagnosis of sciatica (with or without evidence of NRC), the clinical course seemed more favorable compared with those without (ie, those with a diagnosis of referred leg pain). There was some evidence that a higher proportion of patients with a clinical diagnosis of sciatica (with evidence of NRC) may have received more targeted care (eg, epidural injection) compared with those without and compared with those with NP based on s-LANSS. The absolute difference in the numbers receiving more targeted care across the 3 definitions was low and the differences in pain intensity between patients with and without NP based on a clinical diagnosis of sciatica (with or without evidence of NRC) were often small with no obvious clinical relevance. This provides confidence that the course of patients with sciatica (either with or without evidence of NRC) was not confounded by treatment in this cohort and is similar to those without.

The strengths of this research include: (1) the collection of a broad range of self-report data and clinical assessment findings from standardized clinical examinations including MRI scans; (2) the long-term prospective cohort study design allowed for investigation of the temporal relationship between NP at baseline and pain intensity over 3 years, this addresses the limitations of previous research with this patient population, ${ }^{41}$ and; (3) the use of mixed-effect models for repeated measures which take into account fixed effects (presence or absence of NP at baseline), random effects (individual patients), interaction between time and the outcome (pain intensity) and missing data (using likelihood-based approaches) during model development.

\section{Limitations}

Given that a number of characteristics were found to be very strongly associated with NP (eg, neurological examination findings were strongly associated with a clinical diagnosis of sciatica; self-report of burning pain was strongly associated with NP based on s-LANSS), there is a risk of bias due to the incorporation of characteristics that were used to determine cases of NP. Incorporation bias can lead to an overestimation of the strength of an association between a characteristic and 
TABLE 4. Baseline Characteristics of Patients With Neuropathic Pain Based on a Clinical Diagnosis of Sciatica and Evidence of Nerve Root Compression on MRI

\begin{tabular}{|c|c|c|c|}
\hline \multirow[b]{2}{*}{ Characteristics* } & \multicolumn{2}{|c|}{$\begin{array}{c}\text { Neuropathic Pain (Clinical Diagnosis of } \\
\text { Sciatica With Clear or Possible Evidence } \\
\text { of Nerve Root Compression) } \\
\end{array}$} & \multirow[b]{2}{*}{$\begin{array}{c}\text { Unadjusted Odds Ratio } \\
(95 \% \mathrm{CI})\end{array}$} \\
\hline & $\begin{array}{c}\text { Yes, } n=252 \\
(45.5 \%)\end{array}$ & $\begin{array}{c}\text { No, } n=302 \\
(54.5 \%)\end{array}$ & \\
\hline \multicolumn{4}{|l|}{ Sociodemographic characteristics } \\
\hline Female $(\mathrm{n}=554)$ & $137(54.4)$ & $213(70.5)$ & $0.50(0.35,0.70)$ \\
\hline Age $(\mathrm{n}=554)$, mean $(\mathrm{SD})$ & $51.9(13.1)$ & $48.5(14.2)$ & $1.02(1.01,1.03)$ \\
\hline \multicolumn{4}{|l|}{ Socioeconomic status $(\mathrm{n}=540)$} \\
\hline Higher managerial, administrative, and professional occupations & $53(21.7)$ & $70(23.7)$ & 1 \\
\hline Intermediate occupations & $65(26.6)$ & $81(27.4)$ & $1.06(0.65,1.72)$ \\
\hline Routine and manual occupations & $118(48.4)$ & $134(45.3)$ & $1.16(0.75,1.80)$ \\
\hline Never worked and long-term unemployed & $8(3.3)$ & $11(3.7)$ & $0.96(0.36,2.56)$ \\
\hline \multicolumn{4}{|l|}{ Smoking status $(\mathrm{n}=553)$} \\
\hline Never & $93(36.9)$ & $110(36.5)$ & 1 \\
\hline Ex-smoker & $76(30.2)$ & $93(30.9)$ & $0.97(0.64,1.46)$ \\
\hline Current & $83(32.9)$ & $98(32.6)$ & $1.00(0.67,1.50)$ \\
\hline BMI $(\mathrm{n}=549)$, mean $(\mathrm{SD})\left(\mathrm{kg} / \mathrm{m}^{2}\right)$ & $29.8(5.9)$ & $29.1(5.6)$ & $1.02(0.99,1.05)$ \\
\hline \multicolumn{4}{|l|}{ Health status } \\
\hline Self-reported diabetes $(\mathrm{n}=554)$ & $20(7.9)$ & $22(7.3)$ & $1.10(0.58,2.06)$ \\
\hline \multicolumn{4}{|l|}{ Self-reported general health $(\mathrm{n}=553)$} \\
\hline Excellent/very good & $65(25.9)$ & $67(22.0)$ & 1 \\
\hline Good & $66(26.3)$ & $90(29.8)$ & $0.76(0.47,1.20)$ \\
\hline Fair & $100(39.8)$ & $122(40.4)$ & $0.84(0.55,1.30)$ \\
\hline Poor & $20(8.0)$ & $23(7.6)$ & $0.90(0.45,1.79)$ \\
\hline Fatigue $(\mathrm{n}=543)$ & $171(69.5)$ & $209(70.4)$ & $1.04(0.72,1.51)$ \\
\hline Sleep difficulties $(n=549)$ & $211(84.4)$ & $253(84.6)$ & $1.02(0.64,1.62)$ \\
\hline \multicolumn{4}{|l|}{ Pain characteristics } \\
\hline Back pain intensity $(0-10)(n=543)$, mean $(S D)$ & $5.3(1.7)$ & $5.3(1.6)$ & $0.99(0.89,1.10)$ \\
\hline Leg pain intensity $(0-10)(n=542)$, mean $(S D)$ & $6.0(2.3)$ & $4.6(2.3)$ & $1.29(1.19,1.40)$ \\
\hline Constant pain symptoms $(\mathrm{n}=542)$ & $173(70.0)$ & $202(68.5)$ & $1.08(0.75,1.55)$ \\
\hline Pain described as burning pain $(\mathrm{n}=554)$ & $87(34.5)$ & $112(37.1)$ & $0.89(0.63,1.27)$ \\
\hline \multicolumn{4}{|l|}{ Duration of back pain symptoms in current episode $(n=552)$} \\
\hline$<6 \mathrm{wk}$ & $97(38.5)$ & $97(32.3)$ & 1 \\
\hline $6-12 \mathrm{wk}$ & $58(23.0)$ & $58(19.3)$ & $1.00(0.63,1.58)$ \\
\hline$>3 \mathrm{mo}$ & $97(38.5)$ & $145(48.3)$ & $0.67(0.46,0.98)$ \\
\hline \multicolumn{4}{|l|}{ Duration of leg pain symptoms in current episode $(n=530)$} \\
\hline$<6 \mathrm{wk}$ & $106(43.8)$ & $121(42.0)$ & 1 \\
\hline $6-12 w k$ & $57(23.6)$ & $54(18.8)$ & $1.20(0.76,1.90)$ \\
\hline$>3 \mathrm{mo}$ & $79(32.6)$ & $113(39.2)$ & $0.80(0.54,1.18)$ \\
\hline Widespread pain $\dagger(n=540)$ & $71(28.6)$ & $156(53.4)$ & $0.35(0.24,0.50)$ \\
\hline Leg pain worse $(\mathrm{n}=552)$ & $166(66.1)$ & $88(29.2)$ & $4.73(3.30,6.77)$ \\
\hline \multicolumn{4}{|l|}{ Pain location $(\mathrm{n}=554)$} \\
\hline Pain below the knee & $216(85.7)$ & $178(58.9)$ & $4.18(2.74,6.37)$ \\
\hline Pain in 1 leg & $210(83.3)$ & $205(67.9)$ & $2.37(1.57,3.56)$ \\
\hline \multicolumn{4}{|c|}{ Limitations in activities, participation and risk of persistent disabling pain } \\
\hline LBLP-related disability (RMDQ, $0-23)(\mathrm{n}=554)$, mean $(\mathrm{SD})$ & $13.3(5.3)$ & $11.9(5.9)$ & $1.04(1.02,1.08)$ \\
\hline \multicolumn{4}{|l|}{ Risk of persistent disability due to back pain (STarT Back) $(n=530)$} \\
\hline Low risk & $27(11.2)$ & $48(16.3)$ & 1 \\
\hline Medium risk & $116(48.1)$ & 139 (47.1) & $1.48(0.87,2.53)$ \\
\hline High risk & $98(40.7)$ & $108(36.6)$ & $1.61(0.94,2.78)$ \\
\hline \multicolumn{4}{|l|}{ Psychological characteristics } \\
\hline \multicolumn{4}{|l|}{ Depression (HADS) $(\mathrm{n}=554)$} \\
\hline Normal $(0-7)$ & $155(61.5)$ & $200(66.2)$ & 1 \\
\hline Possible (mild) cases $(8-10)$ & $44(17.5)$ & $64(21.2)$ & $0.89(0.57,1.37)$ \\
\hline Probable (moderate/severe) cases $(\geq 11)$ & $53(21.0)$ & $38(12.6)$ & $1.80(1.13,2.87)$ \\
\hline \multicolumn{4}{|l|}{ Anxiety (HADS) $(\mathrm{n}=553)$} \\
\hline Normal $(0-7)$ & $137(54.6)$ & $149(49.3)$ & 1 \\
\hline Possible (mild) cases $(8-10)$ & $50(19.9)$ & $62(20.5)$ & $0.88(0.57,1.36)$ \\
\hline Probable (moderate/severe) cases $(\geq 11)$ & $64(25.5)$ & $91(30.1)$ & $0.76(0.52,1.14)$ \\
\hline Pain self-efficacy (PSEQ, $0-60) \$(n=542)$, mean $(\mathrm{SD})$ & $32.2(14.6)$ & $36.1(14.1)$ & $0.98(0.97,0.99)$ \\
\hline Neurological examination findings & & & \\
\hline Muscle strength $\S(\mathrm{n}=553)$ & & & \\
\hline $5 / 5$ & $191(75.8)$ & $270(89.7)$ & 1 \\
\hline
\end{tabular}


TABLE 4. (continued)

\section{Neuropathic Pain (Clinical Diagnosis of \\ Sciatica With Clear or Possible Evidence of Nerve Root Compression)}

\begin{tabular}{|c|c|c|c|}
\hline \multirow[b]{2}{*}{ Characteristics* } & & \multirow[b]{2}{*}{$\begin{array}{c}\text { Unadjusted Odds Ratio } \\
(95 \% \text { CI })\end{array}$} \\
\hline & $\begin{array}{c}\text { Yes, } n=252 \\
(45.5 \%)\end{array}$ & $\begin{array}{c}\text { No, } n=302 \\
(54.5 \%)\end{array}$ & \\
\hline $4 / 5$ & $50(19.8)$ & $31(10.3)$ & $2.28(1.40,3.70)$ \\
\hline 0 to $3 / 5$ & $11(4.4)$ & 0 & - \\
\hline \multicolumn{4}{|l|}{ Reflex (tendon) change $(n=554)$} \\
\hline None & $169(67.1)$ & $281(93.1)$ & 1 \\
\hline Slightly reduced & $22(8.7)$ & $3(1.0)$ & $12.19(3.60,41.4)$ \\
\hline Significantly reduced or absent & $61(24.2)$ & $18(6.0)$ & $5.63(3.22,9.86)$ \\
\hline \multicolumn{4}{|l|}{ Sensation to pin-prick in the $\operatorname{leg}(\mathrm{s})(\mathrm{n}=554)$} \\
\hline Normal & $125(49.6)$ & $199(65.9)$ & 1 \\
\hline Reduction or loss to pin-prick & $127(50.4)$ & $103(34.1)$ & $1.96(1.39,2.77)$ \\
\hline Presence of allodynia or hyperalgesia in the $\operatorname{leg}(s) \|(n=554)$ & $24(9.5)$ & $30(9.9)$ & $0.95(0.54,1.68)$ \\
\hline Neural tension test (any positive test, $\mathrm{n}=554$ ) & $185(73.4)$ & $122(40.4)$ & $4.07(2.84,5.85)$ \\
\hline Pins and needles in the $\operatorname{leg}(\mathrm{s})(\mathrm{n}=554)$ & $137(54.4)$ & $140(46.4)$ & $1.38(0.99,1.93)$ \\
\hline Pain affects the color of patients skin $(n=554)$ & $28(11.2)$ & $28(9.3)$ & $1.22(0.70,2.12)$ \\
\hline \multicolumn{4}{|l|}{ Pain medication } \\
\hline \multicolumn{4}{|l|}{ No. pain medications $\#(n=554)$} \\
\hline None & $32(12.7)$ & $37(12.3)$ & 1 \\
\hline One & $97(38.5)$ & $124(41.1)$ & $0.90(0.53,1.56)$ \\
\hline Two or more & $123(48.8)$ & $141(46.7)$ & $1.01(0.59,1.72)$ \\
\hline
\end{tabular}

Figures are frequencies (percentages) unless stated otherwise as mean (SD).

Odds ratio (CIs) in italics characteristics associated with neuropathic pain.

* Denominator varies for some characteristics due to missing data or not applicable case.

†Widespread pain was defined as pain present above and below the waist, in the right-hand and left-hand sides of the body and in the axial skeleton.

tHigher scores on PSEQ reflect stronger self-efficacy beliefs

\$Muscle strength was tested according to a 6-point grading scale where; 0. No visible flicker of movement or contraction. 1. Flicker of movement. 2. Full active movement with gravity counterbalanced. 3. Full active movement against gravity but not applied resistance. 4 . Full active movement against gravity and some applied resistance. 5. Full active movement against gravity and strong resistance.

$\|$ Hyperalgesia is an increased pain response to painful stimuli. Allodynia is pain response to nonpainful stimuli (eg, brush strokes).

INeural tension tests; straight leg raise, femoral stretch and slump test.

\#Pain medications include self-reported history of prescribed medications and those purchased over the counter.

BMI indicates body mass index; CI, confidence interval; HADS, Hospital Anxiety and Depression Scale; MRI, magnetic resonance imaging; LBLP, leg pain related to back pain; PSEQ, Pain Self-Efficacy Questionnaire; RMDQ, Roland Morris Disability Questionnaire leg version.

an outcome, in this research NP being the outcome. ${ }^{42}$ However, using 3 accepted NP case definitions, and comparing the characteristics of patients with NP using each definition, adds confidence about the characteristics of these patients. Despite some evidence of incorporation bias, overall there seems to be limited impact on the main findings of the study.

\section{Implications for Clinical Practice and Research}

The implication of using different methods to identify cases of NP is inevitably variation in prevalence estimates, characteristics and clinical course; it is not clear what the implication is in terms of variation in response to treatment. Given the few differences between patients with sciatica with or without evidence of NRC on MRI, both at baseline and in terms of clinical course over 3 years, the clinical implication of our study is that in the absence of widespread or progressive neurological deficit, most LBLP patients with a clinical diagnosis of sciatica (with or without evidence of NRC) should be treated, at least initially, conservatively. Imaging should be reserved for those patients for whom the result is likely to change clinical management. In this research, patients with NP based on s-LANSS had, on average, a more severe phenotype compared with those with NP based on clinical diagnosis, however it is not known if routine use of s-LANSS in clinical practice would benefit patients. Our study provides empirical evidence that questions the usefulness of the hierarchical grading system ${ }^{1}$ to classify cases of neuropathic LBLP by clinical examination. Future epidemiological research is needed to investigate whether characteristics identified from self-report and routine neurological examination that are thought to be important for defining cases of neuropathic LBLP can predict a poor outcome in patients with self-reported signs and symptoms of NP.

\section{CONCLUSIONS}

NP in LBLP patients consulting in primary care is common, with a prevalence between $48 \%$ and $74 \%$ depending on the NP case definition. Many patients with sciatica did not have NP based on s-LANSS, suggesting that sciatica is not always a NP condition. Prevalence and characteristics varied depending on the method used to define NP. At baseline, LBLP-related morbidities such as depression, anxiety, and worse general health were more common in patients with NP based on s-LANSS compared with those with NP based on clinical diagnosis of sciatica. Evidence of NRC from MRI increased the certainty of NP but the prognosis of sciatica patients with or without NRC on MRI, was similar. Our study shows that it is not the presence of NP per se that is associated with poor prognosis, but specifically the presence of self-reported NP. The extent of the improvement in patients with NP depended on the definition of NP, only the 

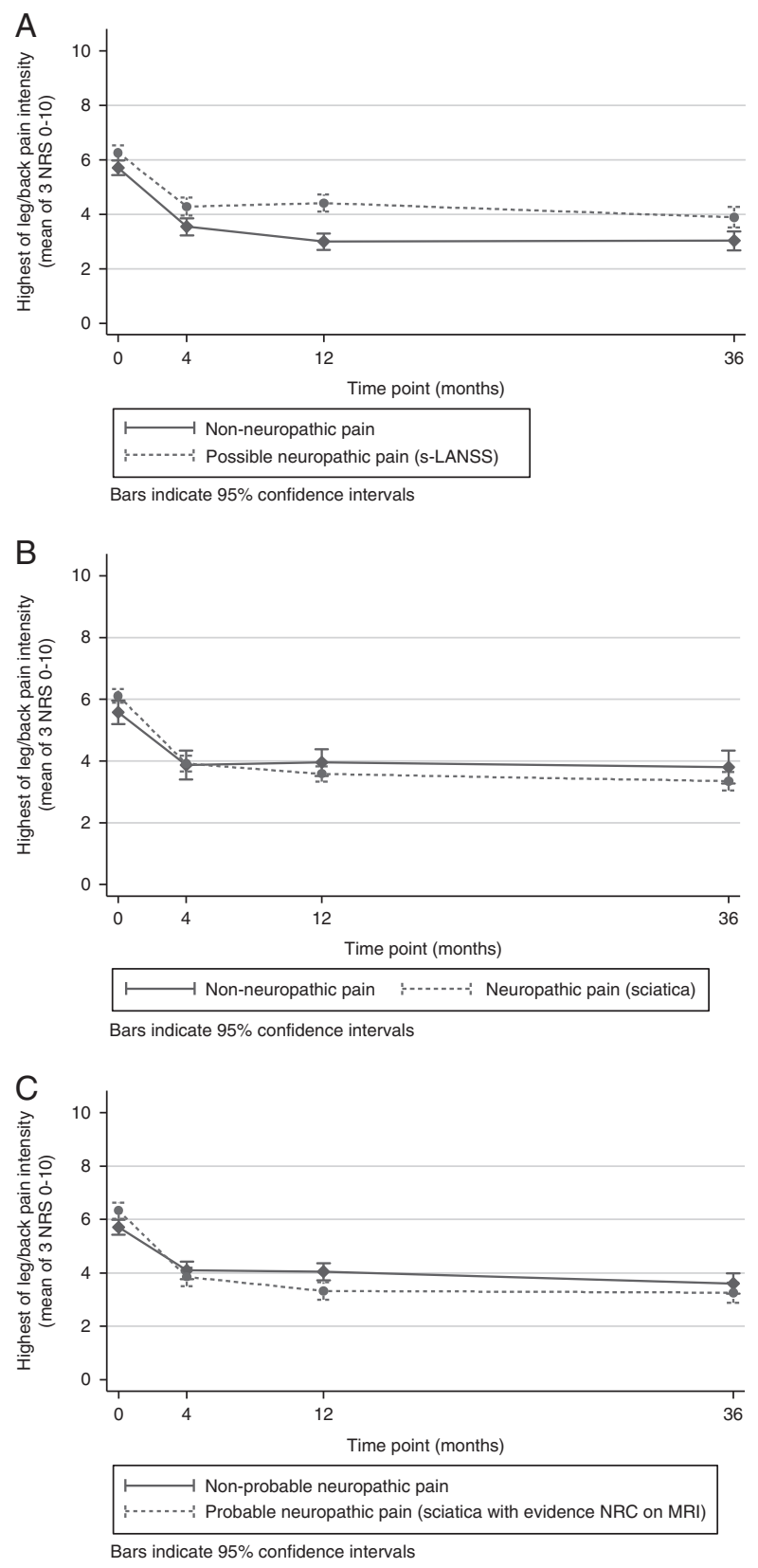

FIGURE 3. Clinical course of patients with and without neuropathic pain. A, Patients with neuropathic pain based on s-LANSS. B, Patients with neuropathic pain defined by clinical diagnosis of sciatica. C, Patients with neuropathic pain defined by clinical diagnosis of sciatica and evidence of nerve root compression on MRI. MRI indicates magnetic resonance imaging; s-LANSS, self-report version of Leeds Assessment for Neurological Symptoms and Signs.

clinical course of LBLP patients NP defined using s-LANSS seemed to be worse compared with those without. This study challenges the commonly held assumptions that the clinical course of NP is mostly poor.

\section{REFERENCES}

1. Treede RD, Jensen TS, Campbell JN, et al. Neuropathic pain: redefinition and a grading system for clinical and research purposes. Neurology. 2008;70:1630-1635.
2. Baron R, Binder A, Wasner G. Neuropathic pain: diagnosis, pathophysiological mechanisms, and treatment. Lancet Neurol. 2010;9:807-819.

3. Breivik H, Collett B, Ventafridda V, et al. Survey of chronic pain in Europe: prevalence, impact on daily life, and treatment. Eur J Pain. 2006;10:287-333.

4. Bennett MI, Smith BH, Torrance N, et al. The S-LANSS score for identifying pain of predominantly neuropathic origin: validation for use in clinical and postal research. J Pain. 2005;6: 149-158.

5. Smith BH, Torrance N, Ferguson JA, et al. Towards a definition of refractory neuropathic pain for epidemiological research. An International Delphi survey of experts. $B M C$ Neurol. 2012;12:29.

6. Berger A, Sadosky A, Dukes E, et al. Clinical characteristics and patterns of healthcare utilization in patients with painful neuropathic disorders in UK general practice: a retrospective cohort study. BMC Neurol. 2012;12:8.

7. Hoy D, March L, Brooks P, et al. The global burden of low back pain: estimates from the Global Burden of Disease 2010 study. Ann Rheum Dis. 2014;73:968-974.

8. Hill JC, Konstantinou K, Egbewale BE, et al. Clinical outcomes among low back pain consulters with referred leg pain in primary care. Spine (Phila Pa 1976). 2011;36:2168-2175.

9. Kongsted A, Kent P, Albert H, et al. Patients with low back pain differ from those who also have leg pain or signs of nerve root involvement - a cross-sectional study. BMC Musculoskelet Disord. 2012;13:236.

10. Konstantinou K, Hider SL, Jordan JL, et al. The impact of low back-related leg pain on outcomes as compared with low back pain alone: a systematic review of the literature. Clin J Pain. 2013;29:644-654.

11. Coggon D, Ntani G, Walker-Bone K, et al. Epidemiological differences between localized and nonlocalized low back pain. Spine (Phila Pa 1976). 2017:42:740-747.

12. Scholz J, Finnerup NB, Attal N, et al. The IASP classification of chronic pain for ICD-11: chronic neuropathic pain. Pain. 2019;160: 53-59.

13. Finnerup NB, Attal N, Haroutounian S, et al. Pharmacotherapy for neuropathic pain in adults: a systematic review and meta-analysis. Lancet Neurol. 2015;14:162-173.

14. National Institute for Health and Care Excellence. Neuropathic pain in adults: pharmacological management in non-specialist settings. NICE guideline CG173; 2013. Available at: http://nice. org.uk/guidance/cg173. Accessed June 3, 2019.

15. Croft P, Dinant GJ, Coventry P, et al. Looking to the future: should 'prognosis' be heard as often as 'diagnosis' in medical education? Educ Prim Care. 2015;26:367-371.

16. Harrisson SA, Stynes S, Dunn KM, et al. Neuropathic pain in low back-related leg pain patients: what is the evidence of prevalence, characteristics, and prognosis in primary care? A systematic review of the literature. J Pain. 2017;18:1295-1312.

17. Konstantinou K, Beardmore R, Dunn KM, et al. Clinical course, characteristics and prognostic indicators in patients presenting with back and leg pain in primary care. The ATLAS study protocol. BMC Musculoskelet Disord. 2012;13:4.

18. Konstantinou K, Dunn KM, Ogollah R, et al. Characteristics of patients with low back and leg pain seeking treatment in primary care: baseline results from the ATLAS cohort study. BMC Musculoskelet Disord. 2015;16:332.

19. Chou R, Qaseem A, Snow V, et al. Diagnosis and treatment of low back pain: a joint clinical practice guideline from the American College of Physicians and the American Pain Society. Ann Intern Med. 2007;147:478-491.

20. Mercer C, Finucane L. Examination of the lumbar region. In Petty NJ, ed. Neuromusculoskeletal Examination and Assessment. A Handbook for Therapists, 4th ed. Edinburgh, New York: Churchill Livingstone/Elsevier; 2011:317-335.

21. Koes BW, van Tulder MW, Peul WC. Diagnosis and treatment of sciatica. BMJ. 2007;334:1313-1317.

22. Konstantinou K, Hider SL, Vogel S, et al. Development of an assessment schedule for patients with low back-associated leg 
pain in primary care: a Delphi consensus study. Eur Spine J. 2012;21:1241-1249.

23. Stynes S, Konstantinou K, Dunn KM, et al. Reliability among clinicians diagnosing low back-related leg pain. Eur Spine J. 2016;25: 2734-2740.

24. Ware JE Jr. SF-36 health survey update. Spine (Phila Pa 1976). 2000;25:3130-3139.

25. Dunn KM, Croft P, Jordan K. Recall of medication use, selfcare activities and pain intensity: a comparison of daily diaries and self-report questionnaires among low back pain patients. Prim Health Care Res Dev. 2010;11:93-102.

26. Roland M, Morris R. A study of the natural history of back pain. Part I: development of a reliable and sensitive measure of disability in low-back pain. Spine (Phila Pa 1976). 1983;8:141-144.

27. Patrick DL, Deyo RA, Atlas SJ, et al. Assessing health-related quality of life in patients with sciatica. Spine (Phila Pa 1976). 1995;20:1899-1909.

28. Zigmond AS, Snaith RP. The hospital anxiety and depression Scale. Acta Psychiatr Scand. 1983;67:361-370.

29. Nicholas MK. The pain self-efficacy Questionnaire: taking pain into account. Eur J Pain. 2007;11:153-163.

30. Ibrahim JG, Chu H, Chen MH. Missing data in clinical studies: issues and methods. J Clin Oncol. 2012;30:3297-3303.

31. StataCorp. Stata Statistical Software: Release 14. College Station, TX: StataCorp LP; 2015.

32. Von Elm E, Altman DG, Egger M, et al. The Strengthening the Reporting of Observational Studies in Epidemiology (STROBE) statement: guidelines for reporting observational studies. Lancet. 2007;370:1453-1457.

33. Gierthmühlen J, Greinacher J, Höper J, et al. Sensory symptoms in low back pain-how do they matter? Curr Med Res Opin. 2017;24:1-12.
34. Walsh J, Hall T. Classification of low back-related leg pain: do subgroups differ in disability and psychosocial factors? $J$ Man Manip Ther. 2009;17:118-123.

35. Schafer A, Hall T, Muller G, et al. Outcomes differ between subgroups of patients with low back and leg pain following neural manual therapy: a prospective cohort study. Eur Spine J. 2011;20:482-490.

36. Morsø L, Kent P, Albert H. Are self-reported pain characteristics, classified using the PainDETECT questionnaire, predictive of outcome in people with low back pain and associated leg pain? Clin J Pain. 2011;27:535-541.

37. Uher T, Bob P. Neuropathic pain, depressive symptoms, and C-reactive protein in sciatica patients. Int J Neurosci. 2013;123: 204-208.

38. Tutoglu A, Boyaci A, Karababa IF, et al. Psychological defensive profile of sciatica patients with neuropathic pain and its relationship to quality of life. $Z$ Rheumatol. 2015;74: 646-651.

39. Artus M, van der Windt D, Jordan KP, et al. The clinical course of low back pain: a meta-analysis comparing outcomes in randomised clinical trials (RCTs) and observational studies. BMC Musculoskelet Disord. 2014;15:68.

40. Green DJ, Lewis M, Mansell G, et al. Clinical course and prognostic factors across different musculoskeletal pain sites: a secondary analysis of individual patient data from randomised clinical trials. Eur J Pain. 2018;22:1057-1070.

41. Hüllemann P, Keller T, Kabelitz $\mathrm{M}$, et al. Pain drawings improve subgrouping of low back pain patients. Pain Pract. 2017;17:293-304.

42. Worster A, Carpenter C. Incorporation bias in studies of diagnostic tests: how to avoid being biased about bias. CJEM. 2008;10:174-175. 